\title{
TOPOGRAPHICAL DISTRIBUTION OF LIPID BIOSYNTHETIC ENZYMES ON PEROXISOMES (MICROBODIES)
}

\author{
James E. Bishop, Mohammed Salem, and Amiya K. Hajra \\ Mental Health Research Institute and \\ Department of Biological Chemistry \\ University of Michigan \\ Ann Arbor, Michigan 48109
}

\begin{abstract}
Recent work ${ }^{1}$ has shown that enzymes of the acyl-DHAP (dihydroxyacetone phosphate) pathway for the biosynthesis of both diacyl-glycerolipids and ether lipids are localized to catalase-containing particles (peroxisomes) in liver. Though the data from the fractionation of brains are less conclusive, it appears that in this organ these enzymes are also localized in the catalase-containing particles (microperoxisomes) ${ }^{1,2}$ In an effort to elucidate the role of acyl-DHAP pathway enzymes in brain microperoxisomal lipid metabolism and in the generation of membrane phospholipid asymmetry, we have determined the distribution of these enzymes in the transverse plane of the microperoxisomal membrane. Specifically, these enzymes are: DHAP acyltransferase (acyl-CoA:DHAP acyltransferase), acyl-CoA reductase (hexadecanol:NADP ${ }^{+}$oxidoreductase, CoAacylating), alkyl-DHAP synthase, and alkyl-DHAP reductase (alkyl-G-3-P: $\mathrm{NADP}^{+}$oxidoreductase).
\end{abstract}

The susceptibility of catalase, an enzyme of the microperoxisomal matrix, to proteolysis was used to determine the integrity of the microperoxisomal membrane. A crude microperoxisomal preparation $(18,000 \times \mathrm{g}, 30 \mathrm{~min}$ to $40,000 \times \mathrm{g}, 30 \mathrm{~min}$ ) from 12-day-old rat brain was preincubated at a concentration of $1 \mathrm{mg}$ protein per $\mathrm{ml} 320 \mathrm{mOs}$ potassium phosphate/sucrose for $30 \mathrm{~min}$ at $37^{\circ} \mathrm{C}$ which contained various amounts of the protease, pronase. When pronase was included in amounts from 0.1-5 $\mathrm{mg}$ pronase $/ \mathrm{mg}$ brain protein, the assay of aliquots for catalase showed that maximally $10 \%$ of the activity was destroyed. These data, plus the observation that $5 \%$ of the homogenate catalase activity is found in the soluble fraction upon subcellular fraction show that $15 \%$ of the microperoxisomes had ruptured membranes. In control experiments to show that catalase was not resistant to pronase digestion, a minimum of $2 \mathrm{mg}$ pronase $/ \mathrm{mg}$ brain protein was found to completely destroy catalase activity when permeabilizing amounts of the detergent Triton X-100 were included in the preincubation. The minimum amount of Triton required to fully permeabilize the membrane was $0.05 \%$.

To determine the transverse distribution of acyl-DHAP pathway enzymes, the crude microperoxisomal preparation was similarly preincubated with trypsin in the presence and absence of permeabilizing amounts of Triton. Trypsin, rather than pronase, was chosen owing to the ease with which it can be inactivated with the addition of trypsin inhibition at the termination of the 30 min preincubation. Assay of aliquots of the preincubation for the four acyl-DHAP pathway enzymes $^{2,3}$ yielded the results presented in TABLE 1.

It can be seen that these enzymes differ in their degree of sensitivity to trypsin digestion (TABLE 1, column 2). An arbitrary choice of trypsin concentration, such as $50 \mu \mathrm{g} / \mathrm{mg}$ protein as used by some workers, ${ }^{4}$ would have resulted in the 
artifactual conclusion that a portion of the acyl-CoA reductase is localized on the internal side of the membrane. A further artifactual assignment of an internal enzyme (such as DHAP acyltransferase) to the external surface was avoided by including permeabilizing amounts of Triton in all enzyme assays. Without Triton in the assay, the destruction by trypsin of a transmembrane protein possibly required for the transport of one of the substrates would have yielded an artifactual measurement of no enzyme activity.

It can be concluded that both DHAP acyl transferase and alkyl-DHAP synthase are on the internal side of the microperoxisomal membrane, and that acyl-CoA reductase is on the external side. The finding that alkyl-DHAP reductase has both internal and external activity might be explained by the fact that this enzyme is not exclusively localized to the microperoxisomes. A significant portion of this activity has been found in the microsomes of both liver and brain. It may be that the enzyme is on the external side of one organelle and the

TABLE 1

Trypsin Proteolysis of ACYl-DHAP PATHWAY ENZYMES IN A CRUDE Microperoxisomal Fraction from 12-DAY RAT BRAIN

\begin{tabular}{|c|c|c|c|c|}
\hline Enzyme & $\begin{array}{c}\mathrm{I}_{50}(+ \text { Triton }){ }^{*} \\
\mu \mathrm{g} \text { Trypsin/mg } \\
\text { Brain Protein }\end{array}$ & $\begin{array}{l}\text { Maximum } \\
\% \text { Activity } \\
\text { Remaining } \\
\text { After } \\
\text { Proteolysis } \\
\text { (-Triton) } \dagger\end{array}$ & $\begin{array}{c}\% \text { of } \\
\text { Enzyme } \\
\text { Internal } \neq\end{array}$ & $\begin{array}{c}\% \% \text { of } \\
\text { Enzyme } \\
\text { External }\end{array}$ \\
\hline DHAP Acyl transferase & 1 & 90 & 106 & -6 \\
\hline Acyl-CoA reductase & 30 & 0 & 0 & 100 \\
\hline Alkyl-DHAP synthase & 40 & 80 & 94 & 6 \\
\hline Alkyl-DHAP reductase & 1 & 30 & 35 & 65 \\
\hline
\end{tabular}

*Amount of trypsin in the preincubation required to destroy $50 \%$ of the enzymes in question in the presence of permeabilizing amounts of Triton X-100 (0.04-0.05\%).

†The intact preparation was preincubated with $0.1-3000 \mu \mathrm{g} t r y p s i n / \mathrm{mg}$ brain protein.

$\Varangle$ Calculated as the number in column 3 divided by $85 \%$, the fraction of microperoxisomes with intact membranes as determined by susceptibility of catalase to proteolysis.

internal surface of the other. It should be noted that the crude microperoxisomal fraction used in this study is heavily contaminated by microsomes.

We have also attempted to determine the topographical distribution of acyl-DHAP-pathway enzymes in liver peroxisomes. One problem encountered was that the liver peroxisomes were much more fragile than the brain microperoxisomes. Approximately $10-30 \%$ of the isolated peroxisomes had ruptured membranes as determined by the absence of catalase or lability of catalase to trypsin in the absence of detergents. However, using the same criteria as discussed above, we concluded that DHAP acyl transferase is mostly present inside the peroxisomes, whereas acyl-DHAP reductase is present on the outside. Alkyl-DHAP synthase was only partly labile indicating that this enzyme may be present on both sides of the membrane. Further work is in progress to discover the significance of the localization of different acyl DHAP pathway enzymes to opposite sides of the peroxisomal and microperoxisomal membranes. 


\section{REFERENCES}

1. HajRa, A. K. \& J. E. Bishop. 1982. Ann. N. Y. Acad. Sci. 386. This volume.

2. Bishop, J. E. 1981. Ph.D. Disseration submitted to the University of Michigan.

3. HajRA, A. K. 1977. Biochem. Soc. Trans. 5: 34-36.

4. Bell, R. M., L. M. Ballas \& R. A. Coleman. 1981. J. Lipid Res. 22: 391-403. 